1970; Pasteels et al., 1971; Billiter and Flückiger, 1971; Hoekfelt and Fuxe, 1972), and there is no evidence that it affects other pituitary hormones. The studies reported here show that it suppresses plasma prolactin levels in man, and it is possible that the drug is acting directly on the pituitary, since it was effective in the patient with a partial hypophysectomy whose pituitary remnant was presumably out of functional contact with the hypothalamus. The drug is effective in suppressing abnormal prolactin-dependent galactorrhoea without side effects in the doses used and at the same time it allows the return of normal menstruation or potency. While the value of oestrogen therapy to suppress puerperal lactation remains controversial it is general experience that it is ineffective in pathological lactation. Levodopa has been used, but while it has appreciable acute effects in lowering the plasma prolactin levels, its effects on the galactorrhoea are inconsistent and may not be sustained (Kleinberg et al., 1971; Friesen et al., 1972; Malarkey et al., 1971; Turkington, 1972).

Treatment with brom-ergocryptine appears to offer a definite advance in the management of patients with galactorrhoea.

We thank Mr. A. Turvey for the histological processing of the cultured mammary glands, the Endocrine Study Section, U.S. National Institutes of Health, for the supply of sheep prolactin, Dr. E. R. Evans and Sandoz Products Ltd. for the provision of brom-ergocryptine (CB 154), Dr. H. G. Friesen for the prolactin immunoassay reagents, and Dr. D. C. Anderson for the plasma 17-OHA measurements. We are grateful to the board of governors of St. Bartholomew's Hospital and the Cancer Research Campaign for financial support, and to Drs. Jean Ginsberg, J. F. Hale, and R. de Mowbray who referred patients.

\section{References}

Anderson, D. C. (1970). Clinica Chimica Acta, 29, 513.

Anderson, D. C., Marshall, J. C., Young, J. L., and Fraser, T. R. (1972). Clinical Endocrinology, 1, 127.

Ben-David, M., Danon, A., and Sulman, F. G. (1971). Fournal of Endocrinology, 51, 719 .

Besser, G. M., and Edwards, C. R. W. (1972). British Medical fournal, 2, 280. Besser, G. M. et al. (1972). British Medical fournal, 3, 267.

Billiter, E., and Flückiger, E. (1971). Experientia, 27, 464.

Flückiger, E., and Wagner, H. R. (1968). Experientia, 24, 1130.

Forsyth, I. A., and Myres, R. P. (1971). Fournal of Endocrinology, 51, 157.

Forsyth, I. A., Besser, G. M., Edwards, C. R. W., Francis, L., and Myres, R. P. (1971). British Medical fournal, 3, 225 .,

Friesen, H. G., Guyda, H., Hwang, P., Tyson, J. E., and Barbeau, A. (1972). fournal of Clinical Investigation, $51,706$.

Hall, R., Ormston, B. J., Besser, G. M., Cryer, R. J., and McKendrick, M. (1972). Lancet, 1, 759 .

Hoekfelt, T., and Fuxe, K. (1972). Neuroendocrinology, 9, 100.

Hwang, P., Guyda, H., and Friesen, H. (1971). Proceedings of the National Academy of Sciences of the United States of America, 68, 1902.

Kamberi, I. A., Mical, R. S., and Porter, J. C. (1971a). Endocrinology, 88, 1288.

Kamberi, I. A., Mical, R. S., and Porter, J. C. (1971b). Endocrinology, 88, 1294.

Kleinberg, D. L., and Frantz, A. G. (1971). Fournal of Clinical Investigation, 50, 1557.

Kleinberg, D. L., Noel, G. L., and Frantz, A. G. (1971). Fournal of Clinical Endocrinology and Metabolism, 33, 873 .

Lutterbeck, P. M., Pryor, J. S., Varga, L., and Wenner, R. (1971). British

Medical fournal, 3, 228.
Malarkey, W. B., Jacobs, L. S., and Daughaday, W. H. (1971). New England fournal of Medicine, 285, 1160 .

Ormston, B. J., Garry, R., Cryer, R. J., Besser, G. M., and Hall, R. (1971).

Lancet, 2, 10.
Pasteels, J. L., Danguy, A., Frerotte, M., and Ectors, F. (1971). Annales d'Endocrinologie, 32, 188.

Turkington, R. W. (1972). Fournal of Clinical Endocrinology and Metabolism, 34, 306 .

Varga, L., Lutterbeck, P. M., Pryor, J. S., Wenner, R., and Erb, H. (1972). Yanai, R., and Nagasawa, H. (1970). Experientia, 26, 649.

\title{
Increasing Frequency of Gall Bladder Operations in the Bristol Clinical Area
}

\author{
C. HOLLAND, K. W. HEATON
}

British Medical fournal, 1972, 3, 672-675

\begin{abstract}
Summary
In the Bristol clinical area the frequency of gall bladder operations rose by a factor of 3.4 between 1940 and 1970, the greatest increase occurring in the 1950s. The increase took place in all age groups, but was greatest in the under30 s and in men. Numerous factors affect the chance of a patient with gall stones being operated on, but a change of this magnitude suggests there has been a substantial rise in the incidence of gall stones since the second world war. This belief is supported by data from the nationwide Hospital In-patient Enquiry.
\end{abstract}

\section{Introduction}

It is commonly stated that gall stones seem to be occurring more often or that the frequency of cholecystectomy is increasing, but there are scant data to support or refute these impressions.

The only completely reliable way of assessing a change in

\footnotetext{
University of Bristol Department of Medicine, Royal Infirmary, Bristol 2

C. HOLLAND, Medical Student

K. W. HEATON, M.D., M.R.C.P., Consultant, Senior Lecturer in Medicine
}

the prevalence of gall stones would be to perform repeated cholecystographic surveys on large, random samples of the general population. No such survey has yet been completed in Great Britain. Necropsy surveys give prevalence data which presumably bear some relation to the prevalence in the general population, but there are no reports of serial necropsy surveys from the same centre covering the postwar period.

At least $98 \%$ of surgical operations on the gall bladder are performed because of gall stones (Andersson et al., 1971). Therefore the frequency of gall bladder operations should reflect the incidence of gall stones. A number of factors may influence the frequency with which patients with gall stones are brought to surgery. The variability of most of these factors is unknown or unmeasurable; some we have tried to assess.

With due regard for these uncertainties we thought it worthwhile to compute the numbers of gall bladder operations performed in the Bristol area in five years for which adequate statistics were available-that is, 1933, 1940,1950, 1960, and 1970. This paper reports our findings-namely, a pronounced rise in the frequency of gall bladder operations and a progressive change in the sex and age incidence of operated subjects since 1940.

\section{Methods}

The Bristol clinical area covers parts of southern Gloucestershire and northern Somerset as well as the city and county of Bristol. It has a population of about 800,000 (Registrar General's annual 
estimates of population of England and Wales). The area is served by 11 hospitals and nursing homes, in nine of which general surgical operations are performed. Complete registers of operations were available from the year 1933 in all of these institutions except one. A nursing home lacked records before 1960 ; in 1960 and 1970 it was responsible for only $1.5 \%$ and $1.3 \%$ of all gall bladder operations, so it was assumed that it provided $1.4 \%$ of the total in the years 1933, 1940, and 1950 . One hospital (Southmead) could not provide full data for 1970, so those for 1969 were used instead.

At each hospital or nursing home the registers of operations were scanned by one of us (C.H.). Details of the patient's age and sex were taken for each entry in which the words cholecystectomy, cholecystostomy, or cholecystolithotomy appeared during the years 1933,1940,1950,1960, and 1970. At one hospital (Bristol Royal Infirmary) a count was also made for the years 1950, 1960 , and 1970 of all general surgical operations-that is, excluding eye, E.N.T., dental, gynaecological, urological, minor casualty, and orthopaedic operations. Figures for the numbers of beds available for general surgery were obtained from the SouthWest Regional Hospital Board.

Differences in the proportion of the population undergoing gall bladder surgery in each year were tested for statistical significance by the $\chi^{2}$ test.

In a subsidiary study the indications for operation were evaluated in all 191 patients undergoing gall bladder surgery at the Bristol Royal Infirmary in 1970. The hospital record of each case was examined by one of us (C.H.), and the nature of the clinical problem allocated to one of nine categoriesemergency operation, previous acute cholecystitis, previous biliary colic, previous obstructive jaundice, previous pancreatitis, carcinoma of the gall bladder, typhoid, painful dyspepsia, and incidental finding of gall stones.

\section{Results}

The total numbers of gall bladder operations for the five years under study were 153 in 1933, 145 in 1940, 231 in 1950, 465 in 1960 , and 623 in 1970 . Thus there was little change between 1933 and 1940 but a pronounced rise in each of the next three decades. The number of operations in 1970 was 4.3 times greater than the number in 1940. The steepest rise (a two-fold one) occurred between 1950 and 1960.

Population growth accounted for only a little of the rise(Fig. 1). The numbers of gall bladder operations per 100,000 population

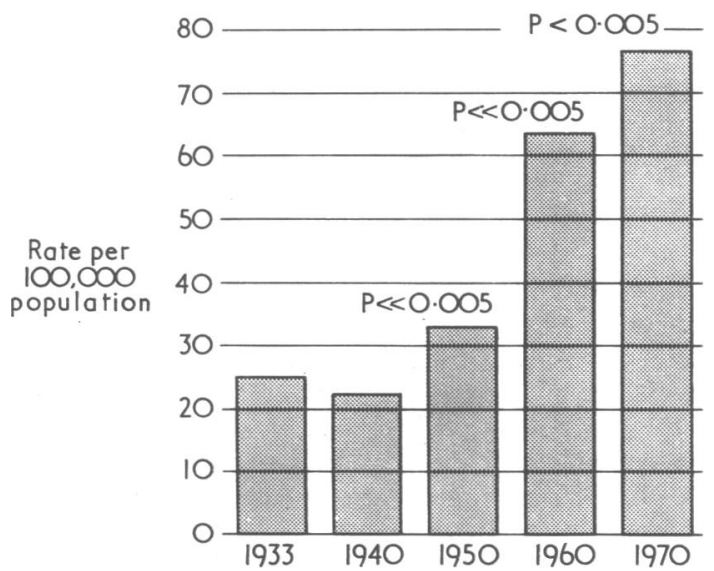

FIG. 1-Rate of gall bladder operations per 100,000 population in the five years under study.

fell slightly and not significantly from 1933 to 1940 , but rose to a highly significant extent in each decade after 1940. Again the steepest rise occurred in the 1950s. Overall the frequency of operations increased by a factor of 3.4 from 1940 to 1970 and by a factor of $2 \cdot 3$ from 1950 to 1970 .
Both sexes shared in the increase (Fig. 2) but it was relatively greater in males, so that the female to male ratio fell from 4.0 in 1950 , through 2.9 in 1960 , to 2.4 in 1970 .

The figures for the entire series analysed by age and sex are given in Fig. 3. In all five years studied the commonest decades

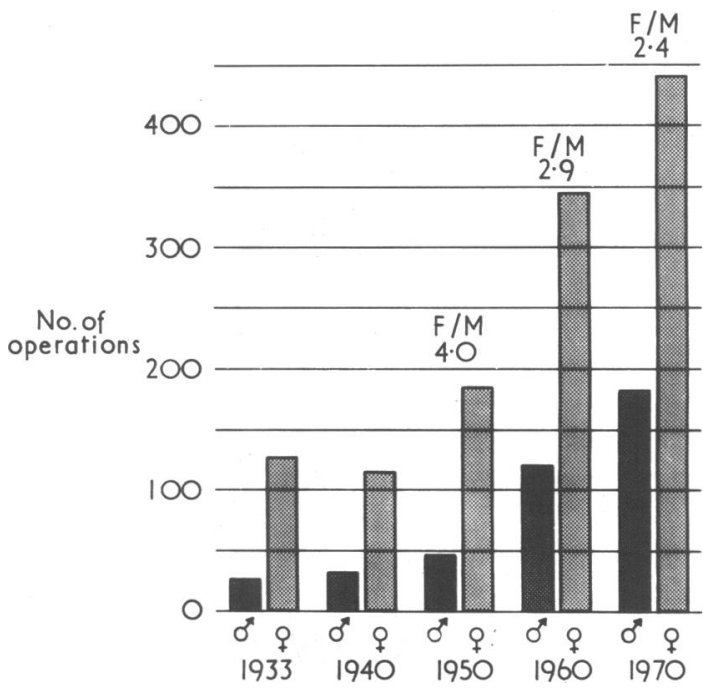

FIG. 2-Numbers of gall bladder operations in males and females in the five years under study.

TABLE I-Number of Gall bladder Operations in Different Age Groups (Percentages are given in Parentheses)

\begin{tabular}{|c|c|c|c|c|c|}
\hline Age & 1933 & 1940 & 1950 & 1960 & 1970 \\
\hline $\begin{array}{ll}\leqslant 29 & . \\
30-59 & . \\
\geqslant 60 & . .\end{array}$ & $\begin{array}{r}5 \\
91(3.6) \\
91(64.5) \\
45(31.9)\end{array}$ & $\begin{array}{r}6 \\
92(4 \cdot 2) \\
45(31 \cdot 3) \\
45(3)\end{array}$ & $\begin{array}{r}9(4 \cdot 0) \\
128(56 \cdot 9) \\
88(39 \cdot 1)\end{array}$ & $\begin{array}{rr}31 & (6 \cdot 7) \\
246 & (53 \cdot 1) \\
186(40 \cdot 2)\end{array}$ & $\begin{array}{rr}58 & (9 \cdot 3) \\
325 & (52 \cdot 3) \\
238 & (38 \cdot 4)\end{array}$ \\
\hline
\end{tabular}

The patient's age was not available in 12 cases in 1933, two in 1940, six in 1950, two in 1960, and two in 1970. These cases have been excluded in calculating the percentages.

in which gall bladder surgery was performed were 50-59 and 60-69. The increase in the number of operations occurred at all ages, but to a significantly greater degree in young peoplethat is, under the age of 30 . As shown in Table $I$ the proportion of all operations performed in the under-30s group increased from $4.0 \%$ in 1950 to $6.7 \%$ in 1960 and to $9.3 \%$ in 1970 . The increase from 1950 to 1970 is statistically significant $(P<0.005)$. Older people did not contribute excessively to the increased number of operations; the proportion of operations in the over60 s remained constant at about $40 \%$.

During the period of greatest increase in gall bladder operations-namely, 1950-70-there was no comparable increase in the number of general surgical operations at the Bristol Royal Infirmary (Table II). Consequently the proportion of operations done on the gall bladder rose from $2.3 \%$ in 1950 to $5.5 \%$ in 1970. The number of hospital beds available for general surgery in the area was exactly the same in 1950 as in 1970 (587).

TABLE II-Numbers of Gall Bladder Operations in Relation to Total General Surgical Operations at Bristol Royal Infirmary

\begin{tabular}{|c|c|c|c|}
\hline & 1950 & 1960 & 1970 \\
\hline $\begin{array}{l}\text { Total general surgical operations } \\
\text { No. of gall bladder operations }(\% \text { of } \\
\text { total) } \quad \ldots \quad \ldots \quad \ldots\end{array}$ & $\begin{array}{c}4,016 \\
93(2 \cdot 3)\end{array}$ & $\begin{array}{c}3,398 \\
150(4 \cdot 4)\end{array}$ & $\begin{array}{c}3,486 \\
191(5 \cdot 5)\end{array}$ \\
\hline
\end{tabular}

The type of gall bladder operation performed changed slightly during the years covered by this study. Cholecystolithotomy was performed in $24 \%$ and $29 \%$ of cases in 1933 and 1940 respectively, in $14.7 \%$ of cases in 1950 , but in only $3 \%$ in 1960 and $0.8 \%$ in 1970 .

The indications for cholecystectomy at the Bristol Royal Infirmary in 1970 are shown in Table III. In all but 3\% of 
cases the indication was a painful condition or jaundice. In only $15 \%$ can there be any doubt whether the operation was necessary to relieve the patients' symptoms - namely, the cases of previous pancreatitis, of dyspepsia, and of gall stones as an incidental finding. Gall stones were found at operation in $188(984 . \%)$ of the 191 patients on whom a cholecystectomy was performed at the Bristol Royal Infirmary in 1970.

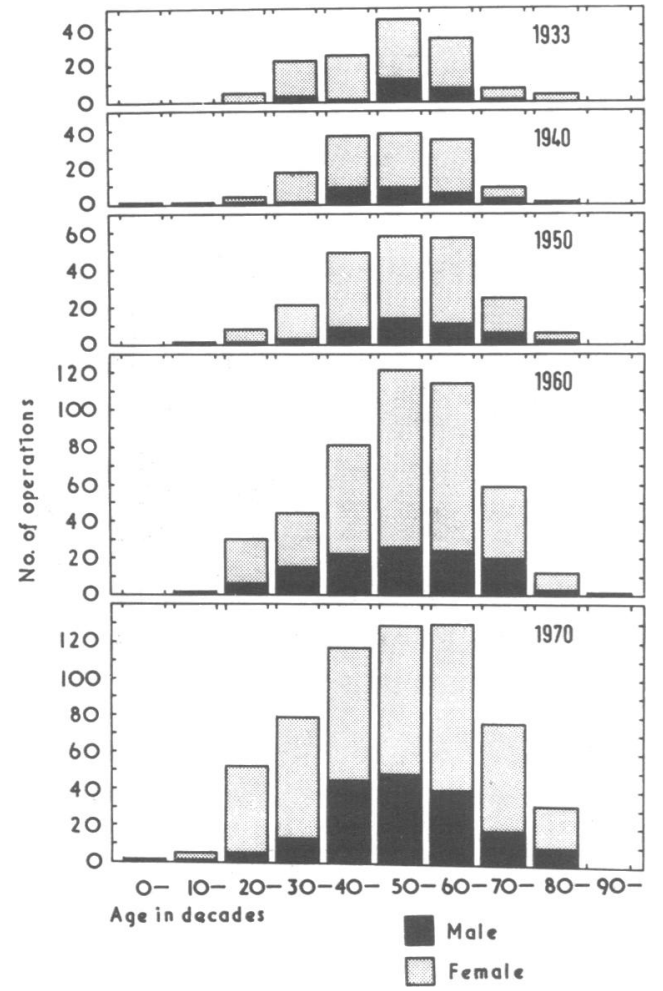

PIG. 3-Distribution of gall bladder operations by age in decades and by sex.

\section{Discussion}

This investigation amply confirms the impression that in England gall bladder operations have become commoner in recent years. It also suggests that the increase in gall bladder surgery is essentially a postwar phenomenon. The increase from 1933 to 1950 was modest and may be an overestimate, since if any records are incomplete they are most likely the early ones. In Gothenburg and Ostersund similar large increases in the frequency of cholecystectomy occurred between the 1940s and the 1950s (Edlund and Olsson, 1956; van der Linden and Rentzhog, 1960).

Before accepting that the increased incidence of gall bladder surgery in Bristol is due to a rise in the incidence of gall stones several other possible causes must be considered.

(1) The character of gall stone disease may have changed so that stones have become more likely to cause symptoms. There is no evidence that such a change has occurred. On the contrary, there is evidence that the tendency of stones to cause symptoms is unrelated to the size, number, or type of stone (Bouchier et al., 1968).

(2) Patients may have become less tolerant of the symptoms of gall stones and so more likely to consult doctors and have their stones diagnosed. This may be so, but $87 \%$ of patients operated on in 1970 had experienced severe symptoms (acute cholecystitis, biliary colic, jaundice, or pancreatitis). It is unlikely that in 1950 many patients with these symptoms failed to seek medical advice or were denied relief by the only certain method of treatment: surgery. A study in Sweden showed that patients with classical biliary pain invariably sought medical advice (van der Linden, 1961).

(3) Doctors may have become more adept at diagnosing gall stones clinically or more suspicious of their presence. There is no evidence for this belief. In any case $85 \%$ of patients operated on in 1970 had clear-cut clinical conditions.

(4) Improvements in radiological technique may have increased the number of gall stones correctly diagnosed and treated. This may be true, but it can hardly explain the major increase since 1950 . In 1950 radiologists were well aware of the limitations of their technique (Gordon, 1953).

(5) Patients may reach surgery more often because of increased availability of surgical services. This is refuted by the absence of any increase in the number of surgical beds in Bristol or in the number of general surgical operations performed.

(6) The indications for surgery may have been relaxed in recent times to include less severe symptoms such as dyspepsia and even asymptomatic gall stones. In 1970, however, only $13 \%$ of cholecystectomies at the Bristol Royal Infirmary fell into these categories. Comparable data could not be collected for the earlier years.

(7) The increase may be partly due to a greater readiness of surgeons to operate for non-lethal conditions and on poor-risk patients. This is unlikely since all age groups shared in the increase; indeed the rise was greatest in the under-30s.

The disproportionate increase in the frequency of cholecystectomy in young people and the greater increase in men than in women is suggestive of a genuine change in the pattern of gall stone disease. In Sweden, too, there has been a particularly sharp increase in gall bladder operations in males and in the young (Edlund and Olsson, 1956; van der Linden and Rentzhog, 1960). Since the 1950s gall bladder operations have not been uncommon in Swedish children (Nilsson, 1966). There is good evidence from necropsy surveys that in Sweden gall stone prevalence rose markedly between the 1930s and the 1960 s (Sternby, 1968). If gall stones are environmental in origin then it is to be expected that more intense exposure of the whole population to the aetiological factor (or factors) will result not only in a greater overall incidence but also in the appearance of the disease in younger subjects.

The belief that gall stones are becoming commoner is supported at a national level by the Reports on Hospital In-patient Enquiry (General Register Office, 1961-70). These show that over the nine-year period 1958-67 the estimated discharge rate from N.H.S. hospitals in England and Wales of patients diagnosed as having diseases of the gall bladder and biliary ducts rose steadily from $8 \cdot 4$ to $10 \cdot 2$ per 10,000 population. This is equivalent to a $24 \%$ rise in 10 years, which compares with a $19.4 \%$ rise in the rate of gall bladder surgery in the Bristol area between 1960 and 1970. The reports also support the suggestion that gall stones are occurring in younger people. In 1958 the estimated discharge rates with diseases of the gall bladder and biliary ducts in subjects aged 15 to 44 were 1.7 per 10,000 for males and 7.0 per 10,000 for females. By 1966 these had risen to 2.6 and 9.3 respectively - that is, by $53 \%$ and $33 \%$-whereas in the same period the rates for males and females of all ages had risen by only $36 \%$ and $11 \%$ respectively. The reports also agree that the female to male ratio is falling. From 1958 to 1967 the overall male rate rose from 4.2 to 6.2 -that is, by $48 \%$-and the overall female rate rose from $12 \cdot 3$ to $14 \cdot 1$-that is, by $15 \%$.

TABLE III-Indications for Surgery in 191 Patients who underwent Cholecystectomy in 1970 at Bristol Royal Infirmary

\begin{tabular}{|c|c|c|c|c|c|c|c|}
\hline & $\begin{array}{c}\text { Emergency } \\
\text { Operation }\end{array}$ & $\begin{array}{c}\text { Previous Acute } \\
\text { Cholecystitis }\end{array}$ & $\begin{array}{l}\text { Previous Biliary } \\
\text { Colic }\end{array}$ & $\begin{array}{c}\text { Previous Obstructive } \\
\text { Jaundice }\end{array}$ & $\begin{array}{c}\text { Previous } \\
\text { Pancreatitis }\end{array}$ & $\begin{array}{c}\text { Painful } \\
\text { Dyspepsia }\end{array}$ & $\begin{array}{l}\text { Incidental Finding } \\
\text { of Gall Stones }\end{array}$ \\
\hline No. $(\%)$ of patients & $37(19 \cdot 4)$ & $79(41 \cdot 4)$ & $38(19.9)$ & $8(4 \cdot 2)$ & $4(2 \cdot 1)$ & $19(9.9)$ & $6(3 \cdot 1)$ \\
\hline
\end{tabular}


Consequently the female to male ratio fell from $2 \cdot 9$ to $2 \cdot 3$. In the present study the ratio fell from 2.9 to 2.4 over a similar period.

Two incidental findings in this study deserve comment. Firstly, cholecystolithotomy virtually disappeared as an operation for gall stones in the 1950s and 1960s, presumably because of the high recurrence rate when the gall bladder is left in situ. Most recurrences occur within the first few years (Norrby and Schonebeck, 1970), so it is unlikely that a significant number of patients were counted twice in the present study. Secondly, the 40-49 decade was at no time the commonest decade for undergoing cholecystectomy, which further discredits the old jingle that the typical gall stone sufferer is fair, fat, fertile, and forty.

Requests for reprints should be addressed to Dr. K. W. Heaton, University of Bristol Department of Medicine, Royal Infirmary, Bristol 2.

\section{References}

Andersson, A., Bergdahl, L., and Boquist, L. (1971). American fournal of Surgery, 122, 3 .

Bouchier, I. A. D., Rhodes, K., and Brien, M. (1968). Scandinavianfournal of Gastroenterology, 3, 299.

Edlund, Y., and Olsson, O. (1956). Acta Chirurgica Scandinavica, 111, 481.

General Register Office (1961-70). Reports on Hospital In-patient Enquiry, 1958-67. London, H.M.S.O.

Gordon, I. R. S. (1953). Quarterly Fournal of Medicine, 46, 261.

Nilsson, S. (1966). Acta Chirurgica Scandinavica, 132, 275.

Norrby, S., and Schonebeck, J. (1970). Acta Chirurgica Scandinavica, 136, 711.

Sternby, N. H. (1968). Acta Pathologica et Microbiologica Scandinavica, Suppl. No. 194.

van der Linden, W. (1961). Acta Chirurgica Scandinavica, Suppl. No. 269.

van der Linden, W., and Rentzhog, U. (1960). Acta Chirurgica Scandinavica, $119,489$.

\title{
Insulin, Glucose, and Potassium in the Treatment of Congestive Heart Failure
}

\author{
S. P. ALLISON, C. J. MORLEY, C. J. BURNS-COX
}

British Medical fournal, 1972, 3, 675-678

\section{Summary}

A daily infusion of $500-1,000 \mathrm{ml}$ of $50 \%$ glucose containing 100-120 units of soluble insulin and 100-120 $\mathrm{mEq}$ of potassium chloride per litre was given to six patients suffering from hyponatraemia and congestive cardiac failure resistant to digoxin and diuretic therapy. In two patients there was no response, but four showed a striking improvement with a sodium and water diuresis, a rise in plasma sodium level, and in two cases a reversion from atrial fibrillation to sinus rhythm. It is suggested that insulin, glucose, and potassium given by the intravenous route in adequate dosage forms a useful adjunct to the management of severe congestive heart failure.

\section{Introduction}

Insulin has been said to be useful in the treatment of congestive heart failure (Flear, 1966; Sodi-Pallares et al., 1969), but this has been obscured by the controversy over its use after myocardial infarction (Medical Research Council Working Party, 1968). Sodi-Pallares et al. (1969) pointed out that in studies which purported to test their insulin, glucose, and potassium regimen, the dose and route of administration were different from those which they recommended. Flear ascribed its effect to enhancement of the sodium pump and to reversal of the high intracellular sodium content which poisons myocardial activity. The effect of insulin and glucose in burnt patients has been reported (Hinton and Allison, 1969; Hinton et al., 1971). In these patients a large sodium diuresis, a rise in plasma sodium level, and lower urinary nitrogen and potassium losses were found. In view of the similarity between the electrolyte abnormalities in burnt patients and those in severe congestive heart failure it was

Department of Medicine, Bristol Royal Infirmary

S. P. ALLISON, M.D., M.R.C.P., Wellcome Senior Research Fellow (At present: Consultant Physician, Nottingham General Hospital)

Frenchay Hospital, Bristol

C. J. MORLEY, M.B., M.R.C.P., Senior House Officer

C. J. BURNS-COX, M.D., M.R.C.P., Consultant Physician decided to assess the value of the insulin, glucose, and potassium regimen in the cardiac patients of our own hospitals, selecting patients in whom conventional therapy had failed.

\section{Patients and Methods}

Six patients were studied, each of whom had been referred by a consultant cardiologist because of failure to respond to conventional treatment with digoxin and diuretics. They were all suffering from severe congestive cardiac failure and hyponatraemia.

The insulin, glucose and potassium regimen was similar to that described previously (Hinton et al., 1971). A total of $500-1,000 \mathrm{ml}$ of $50 \%$ glucose containing 100-120 units of soluble insulin/l. and $100-200 \mathrm{mEq}$ of potassium chloride/l. was given daily. The mixture was infused at $40 \mathrm{ml} / \mathrm{hr}$ through a central venous catheter and flushed in with $5 \%$ glucose via a three-way tap. All urine samples were tested for sugar by the Clinitest method, and frequent measurements of blood glucose were made with Dextrostix. The amount of insulin was then adjusted to obtain up to $1 \%$ glycosuria with a blood glucose between 100 and $150 \mathrm{mg} / 100 \mathrm{ml}$. Twice-daily measurements of plasma potassium were made and the potassium chloride content of the infusion was adjusted accordingly. Continuous E.C.G. monitoring was carried out with an oscilloscope and a careful watch maintained for any rhythm changes. The patients were weighed at least once a day and fluid balance was charted. Estimations of urea, sodium, potassium, chloride, and bicarbonate were made in sequential 24-hour urine collections and in twice-daily plasma samples by using autoanalyser techniques. Urine volumes were measured two-hourly in Case 1 (see Fig. 1) and 12-hourly in Cases 2 to 4 in order to correlate changes in urine volume, weight, and plasma sodium concentration with insulin and glucose infusions over short periods of time.

\section{Results}

Two patients derived no benefit from the treatment and died a few days later. The other four showed a striking response in terms of sodium and water diuresis, with a rise in plasma sodium concentration. Two of these showed a reversal from atrial fibrillation to sinus rhythm. 